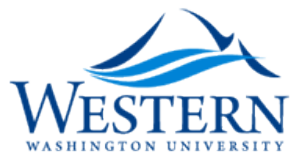

Western Washington University

Western CEDAR

1993

\title{
Strong Agreement and Identification: Evidence from Ellipsis in English
}

Anne C. Lobeck

Western Washington University, anne.lobeck@wwu.edu

Follow this and additional works at: https://cedar.wwu.edu/english_facpubs

Part of the English Language and Literature Commons

\section{Recommended Citation}

Lobeck, Anne. "Strong Agreement and Identification: Evidence from Ellipsis in English." Linguistics 31.5 (1993): 777-811.

This Article is brought to you for free and open access by the English at Western CEDAR. It has been accepted for inclusion in English Faculty and Staff Publications by an authorized administrator of Western CEDAR. For more information, please contact westerncedar@wwu.edu. 


\section{Strong agreement and identification: evidence from ellipsis in English*}

ANNE LOBECK

\section{Abstract}

I propose that ellipted constituents in English DP ( $N^{\prime}$ ellipsis), $C P$ (sluicing), and IP (VP ellipsis) are empty, non-NP pronominals, licensed and identified under the same condition that constrains nonarbitrary NP pro: [e] must be governed by an X-O specified for strong agreement. Strong agreement must be broadened to include features that identify non-NP pro, an empty category that crucially differs from NP pro in also requiring reconstruction for its content to be fully recovered. The analysis explains several ungrammatical ellipsis patterns in $D P, C P$, and $I P$, and why ellipsis fails in lexical categories and the functional category DEGP in English. The account is supported by ellipsis patterns in German, French, and Malay.

\section{Introduction}

In Lobeck (1991a) I argue that the "ellipted" categories in (1)-(3), empty constituents typically interpreted under identity with a linguistic antecedent, are constrained by the ECP in (4):

(1) Ellipsis in IP (VP ellipsis):

a. Because [Pavarotti couldn't [e]], they asked Domingo to sing IP VP the part.

b. Lee wants to leave but [Sue doesn't want to [e]]. IP VP

(2) Ellipsis in NP:

a. Although John's friends were late to the rally, [Mary's [e]] arrived on time.

NP $\quad \mathrm{N}^{\prime}$ 
b. Mary enjoyed the movies, and [both [e]] were also interesting NP $N^{\prime}$ to Sue.

(3) Ellipsis in CP (sluicing):

a. We want to invite someone, but we don't know [who [e]].

b. Mary decided to go to Hawaii though she wouldn't tell us [why [e]].

CP IP

(4) The empty-category principle:

$\left[{ }_{a} \mathrm{e}\right]$ must be properly governed.

In that work I argue that the means by which ellipses satisfy the ECP is expressed by the licensing principle in (5):

(5) The ellipsis licensing principle: ${ }^{1}$

An ellipsis must be governed by a functional head specified as [+Plural], [+ Poss], [+ Tense, +AGR], or [+WH].

I base this conclusion on evidence that ellipted constituents across what I argue to be DP, IP, and CP in English form a natural syntactic class of empty elements that are well formed only when governed by a "functional" (DET, COMP, INFL) as opposed to "lexical" category (N, V, A, or P) specified for certain features. In this way, we explain the contrast between the grammatical sentences in (1)-(3) and their ungrammatical counterparts in (6)-(8) below (where ellipsis in NP is reanalyzed as ellipsis in DP).

(6) *John took off work to go on vacation, and

Bill also took some time off [PRO to [e]].

IP VP

(7) *The candidates came in and [every [e]] sat down.

DP

(8) *Although [whether/if [e]] is unclear, Sue still thinks John made it CP IP

to work on time.

It is possible to argue that in each of the above cases the ellipted category is governed by a head DET, COMP, or INFL that lacks the appropriate feature specification required by the ELP. The ellipsis violates the ECP and is ruled out. ${ }^{2}$

Though the ELP accounts for a wide range of data not typically addressed in discussions of ellipsis, the principle also raises certain questions, which are the topic of discussion here. For example, can the ELP be derived from independent principles of licensing and identification 
argued to hold of more well studied empty categories? We would expect this to be the case in a "principles and parameters" framework such as government and binding. More specifically, we might expect there to be a connection between the ELP and the (informally stated) condition in (9), widely assumed to be a necessary but not sufficient condition on empty pronominal arguments such as the empty Spanish subjects in (10)-(11).

(9) A nonarbitrary, empty pronominal must be governed by an X-0 specified for "strong" agreement.

[e] dijo que [e] mató al perro.

'(He/she) said that (he/she) killed the dog.'

(11) [e] siempre habla de sí mismo.

'(He) always talks about himself.'

I argue here that both the ELP and (9) derive from a broader licensing and identification principle, and that this is not accidental given independent evidence, including that presented by Chao (1987), that ellipted categories are empty pronominals, or "non-NP" pro. In particular, I argue, based on evidence from English, French, German, and Malay, that empty, nonarbitrary NP and non-NP pronominals are licensed and identified under (12):

\section{Licensing and identification of empty pronominals: ${ }^{3}$}

An empty, nonarbitrary pronominal must be governed by an X-0 specified for strong agreement.

(12) not only predicts the contrast between the grammatical (1)-(3) and the ungrammatical (6)-(8), but it also explains why ellipsis is uniformly ruled out in lexical categories in English, and in functional categories other than DP, CP, and IP, namely DEGP. Further, that (12) holds of both referential empty "NP" or, as I argue, "DP" pro, and nonreferential empty "non-DP" pro suggests an interesting distinction between the two types of empty pronominals with respect to identification. I argue that while (12) is the means by which the referential content of a nominal pro is recovered, it is also the means by which a nonnominal, nonreferential pro is made "visible" to reconstruction, the process by which the semantic content of the empty category is recovered.

\section{The typology and interpretation of ellipted categories}

\subsection{Ellipses as empty pronominals}

Synthesizing arguments presented by Jackendoff (1971), Hankamer and Sag (1976), Sag (1976), and Williams (1977), it is possible to claim that 
the empty categories in (1)-(3) in English form a natural syntactic class, distinct from the empty elements that arise from gapping, stripping, and null complement anaphora. I will assume this distinction henceforth. ${ }^{4}$ Here, I discuss only a set of characteristics, including some presented by Chao (1987: ch. 4), which justify the claim that ellipses are best analyzed as empty pronominals. A list of the relevant properties of ellipsis is given in (13):

\section{(13) Ellipsis:}

a. an ellipsis can occur in either a coordinate or subordinate clause separate from that containing its antecedent;

b. ellipsis can occur across "utterance boundaries";

c. ellipsis obeys the backwards anaphora constraint;

d. an ellipsis can have a pragmatic or syntactic antecedent;

e. an ellipsis can have a split antecedent.

(13a) is illustrated by the sentences in (14), in which ellipses in IP, $\mathrm{NP}$, and CP can occur in either subordinate or coordinate clauses that do not also contain their antecedents:

(14) a. Mary met Bill at Berkeley and [Sue did [e]] too.

IP

b. Mary met Bill at Berkeley although [Sue didn't [e]].

IP

c. We liked some wines from France although/but [most [e]] were NP too dry.

d. We want to invite someone but/although we don't know [who [e]]. $\mathrm{CP}$

(15) shows that ellipted categories can occur across "utterance boundaries" as stated in (13b); an ellipsis can be contained in an utterance separate from that containing its antecedent.

(15) A: John caught a big fish.

B a. Yes, but Mary didn't [e]. (IP)

b. Yes, but Mary's [e] was bigger. (NP)

c. Yes, but we don't know how [e]. (CP)

(16) illustrates that as stated in (13c), ellipses obey the backwards anaphora constraint (Langacker 1966), which means that they can precede, but not command, their antecedents. This is illustrated by the grammaticality of sentences in which the ellipsis precedes its antecedent when contained in a subordinate clause, and the contrasting ill- 
formedness of sentences in which the ellipsis preceding its antecedent is contained in a main clause:

(16) a. Because [Sue didn't [e]], John ate meat.

$$
\text { IP }
$$

b. $\quad{ }^{*}$ [Sue didn't [e]] because John ate meat.

IP

c. Although [most [e]] were too dry, we liked some wines from NP

France.

d. * $[$ Most $[e]]$ were too dry, although we liked some wines NP from France.

e. Even though [we don't know who [e]], we want to invite CP someone.

f. "We don't know [who [e]], even though we want to invite $\mathrm{CP}$ someone.

From the data in (14)-(16), we see that there is no evidence that ellipses in IP, NP, and CP are derived by movement. There is also no evidence that ellipted categories are in any obvious way A-bar bound, for example by an empty operator, nor are ellipses A-bound to antecedents in their containing clauses. Ellipses are thus neither variables nor anaphors. ${ }^{5}$ Ellipses do, however, obey the backwards anaphora constraint, a property of pronouns, and seem also to be constrained by principle B of the binding theory in (17); they are free in their containing $\mathrm{S}$ or NP and are interpreted under identity with an antecedent in the surrounding discourse.

(17) Binding theory (Chomsky 1986a: 166):

(A) an anaphora is bound in a local domain;

(B) a pronominal is free in a local domain;

(C) an r-expression is free (in the domain of the head of its chain).

Ellipses thus pattern with ordinary pronouns, elements that also satisfy the criteria in (13a)-(13c) discussed above. For example, pronouns can occur in coordinate or subordinate clauses separate from those containing their antecedents, as in (18):

(18) Sue eats fish because/and she hates meat.

Pronouns also occur across utterance boundaries, as in (19): 

A. Does Sue eat fish?
B. Yes, but she hates it.

And finally, like the ellipted categories in (16), pronouns are subject to the backwards anaphora constraint; they cannot precede their antecedents unless contained in a subordinate clause:

(20) a. Because she doesn't like meat, Sue ate fish.

b. *She doesn't like meat because Sue hates killing animals.

Turning now to (13d)-(13e), in Chao's (1987: ch. 4) discussion of ellipsis in IP and CP, she argues that like pronouns, ellipses need not always have syntactic antecedents; they may also have pragmatic or discourse antecedents. For example, the pronouns he, she, and it in (21) are all pragmatically interpreted (from Chao 1987: 129).

(21) [John walks into the kitchen and finds milk spilled all over the floor and two guilty-looking kids. John:]

a. All right, who did it?

b. He did it.

c. No, I didn't. She did it.

Like the pronouns in (21), the ellipted VPs in (22) can also have pragmatic antecedents; the sentences can all be uttered in contexts in which a syntactic antecedent is not required (Chao 1987: 134):
a. You shouldn't have [e]!
b. Don't [e].
c. I will [e] if you do [e].

This possibility also holds for ellipsis in $\mathrm{CP}$, or sluicing, as we see in (23) (Chao 1987: 124):

(23) [John is in a used-car lot, and the salesperson approaches with her sales pitch:]

Salesperson: Look at this beautiful Mustang.

John:

OK, but first tell me how much [e].

Extending Chao's observation to ellipsis in NP, Lobeck (n.d.) points out that ellipted nominal projections can also be quite productively pragmatically interpreted:

(24) [Sarah and Geoff have two sons, Charlie and Sam. The two boys are playing with their new toys. Charlie's breaks.]

Sarah: Sam's [e] better not do that.

Geoff: Some [e] are just poorly made, I guess. 
And finally, as stated in (13e), ellipses can have "split" antecedents, a property typically associated with pronouns. For example, in (25), the antecedent for the empty pronominal anaphor PRO includes both the matrix subject and object.

(25) Jack proposed to Jill [PRO to help each other].

The ellipted VPs in the following examples can also have "split" antecedents. (These examples are from a talk by D. Hardt at the Ellipsis Workshop in Stuttgart. Thanks also to A. Hestvik for useful discussion on this point).

a. So I say to the conspiracy fans: leave him alone.

Leave us alone. But they won't [e]. (Welcomat 1992).

b. I can walk, and I can chew gum.

Gerry can [e], too, but not at the same time (Webber 1978).

c. Wendy is eager to sail around the world and Bruce is eager to climb Kilimanjaro, but neither of them can [e] because money is too tight (Webber 1978).

It therefore seems to be the case that ellipted categories pattern with ordinary pronominals NPs. This is not necessarily surprising, but rather expected, under the assumption that all empty categories are typologically (+/-anaphor, +/-pronominal]. That ellipses can be analyzed as also falling under this typology is therefore a welcome result in a "principles and parameters" model of grammar.

Nevertheless, if we are to fully justify the claim that ellipses are [-anaphor, + pronominal] empty categories within a government-binding framework, we must first determine whether ellipses, like NP pro, can be argued to be base-generated empty categories. Second, we expect to find that ellipses are licensed and identified in a way similar to NP pro.

In the following section I discuss an approach to the interpretation of ellipses under which it is indeed possible to argue that ellipses are basegenerated empty elements. We shall also see, however, that ellipses crucially differ from empty pronominal NPs in the way in which the content of the empty category is recovered.

\subsection{Recoverability strategies for empty pronominals}

Though analyses vary, the content of an empty pronominal argument is typically argued to be recovered through association with agreement features of person and number (and also gender, if present), which are morphologically realized on an X-0 governing pro. We can thus say 
(modulo the comments in note 3 ) that empty pronominal arguments are licensed and identified under (27). (27) therefore entails the means by which empty pronominals satisfy the ECP, if we take the ECP to be a condition of licensing.

(27) An empty, nonarbitrary pronominal must be governed by an X-0 specified for "strong" agreement.

I define "strong" agreement as in (28), based on work by Jaeggli and Safir (1989), who attempt to synthesize a number of different approaches to this idea.

(28) Strong agreement (based on Jaeggli and Safir 1989):

An X-0 is specified for strong agreement iff

(i) the X-0 or a phrase or head coindexed with it is specified for agreement, and

(ii) agreement is morphologically realized on $\mathrm{X}-0$ or on the phrase or head coindexed with it.

According to (28), a head is specified for strong agreement if (i) it is either itself specified for agreement features or coindexed with an element that is so specified, and (ii) agreement features are morphologically realized on X-0 or the element with which it is coindexed. In (10)-(11), for example, repeated here as (29)-(30), Spanish INFL morphologically realizes features of person and number and is therefore specified for strong agreement under (30).
(29) $[\mathrm{e}]$
dijo
gue [e]
mató al perro.
'(He/she) say-3rd-sg that (he/she) killed the dog.'
[e] siempre habla de si mismo.
'(He) always talk-3rd-sg about himself.'

The features of INFL in Spanish supply the necessary content of pro, allowing it to be interpreted as an (empty) NP pronoun. Because English INFL fails to morphologically realize agreement in the appropriate way, it is not specified for strong agreement, and pro subjects in English are consequently disallowed.

(27)-(28) also explain cases in which INFL may not be specified for strong agreement but can apparently "inherit" strong agreement from a higher source. For example, Borer (1989) observed that in Hebrew, empty subjects of certain tensed embedded clauses are only well formed if coreferential with a higher subject, as in (31a). If the embedded subject is not coreferential, it cannot be empty, as we see in ( $31 \mathrm{~b})$. 
(31) a. Talila $a_{\mathrm{j}}$ Pamra le-Itamar she pro $_{\mathrm{j}}$ tavo.

Talila said to-Itamar that pro will-come-F-SG

'Talila told Itamar that she will come.'

b. Talila $a_{\mathrm{j}}$ Pamra le-Itamar she hem ${ }_{\mathrm{k}} /{ }^{*}$ pro $_{\mathrm{k}}$ yavo?u.

Talila said to-Itamar that they $/{ }^{*}$ pro will-come-M-PL.

'Talila told Itamar that * (they) will come.'

Borer claims that, under certain conditions, lower AGR is anaphoric and must be controlled by a higher AGR. This condition is met in (31a), but not (31b). Huang (1984) makes a similar claim for Chinese, namely that lower INFL must be controlled by a higher INFL in order to identify a coreferential, embedded pro subject (see also Huang 1989).

Jaeggli and Safir (1989) suggest that patterns such as that exemplified in (31) can be derived from a framework in which pro is identified not through principles of control but rather through a version of (27), taken together with strong agreement as defined in (28). They explain the data in (31) by proposing that AGR either can be specified for strong agreement or can "inherit" those features from a c-commanding (and I assume coindexed) NP. In Hebrew or Chinese, languages in which AGR is not strong enough to identify empty NP, AGR in an embedded clause such as (31a) can only "inherit" strong agreement from a higher NP, explaining the evidence that pro must be coreferential to that NP if the sentence is to be grammatical. They thus explain the occurrence of pro in these cases without appealing to control theory.

Turning now to ellipsis, it has been widely argued that the content of an ellipsis, in particular the content of an ellipted VP, cannot be recovered under identity of reference with an antecedent. Ellipses thus contrast with referential NPs, in particular empty, nonarbitrary NP pronouns. ${ }^{6}$

To express the distinction between referential elements and ellipses, Grinder and Postal (1971) propose that proforms (lexical pronouns) are identity of reference anaphora (IRA), and that ellipses, which they assume are derived by deletion, are identity of sense anaphora (ISA). Williams (1977: note 6) suggests that differences in interpretation strategies between ellipses and referential pronouns are reflected by a categorial (NP versus non-NP) distinction; only NPs can be referential, while (empty) elements other than NPs must be interpreted by grammatical processes other than reference.

Translating the above distinctions into terms consistent with current government-binding theory and the assumptions made here, I propose that there is a split between pronominals that are identical in reference to their antecedents and those identical in sense to their antecedents. The former include nonarbitrary NPs, which, when empty, can be interpreted 
through association with referential features of person, number, and gender. The latter type of pronominal includes empty non-NPs, elements that must be interpreted by some strategy other than reference.

To formally express the difference in interpretation between referential NPs and nonreferential ellipted categories, Partee (1973), Sag (1976), and Williams (1977) all argue in different frameworks that it is the "logical form" of the antecedent rather than its surface syntactic representation that is relevant to the interpretation of an ellipted category. One reason for this claim is that ellipted VPs exhibit certain ambiguities with respect to pronoun interpretation. For example, consider (32) and (33): ${ }^{7}$

(32) Charlie likes his kids and Geoff does [e] too.

(33) Sue likes herself and Mary does [e] too.

$$
\text { VP }
$$

VP

In (32, the ellipted VP can be interpreted as including a pronoun with either a "strict" or "sloppy" interpretation; [e] can mean either that Geoff likes Charlie's kids, the "strict" reading, or that Geoff likes his own kids, the "sloppy" interpretation. In contrast in (33), the reflexive anaphor can only have the "sloppy" interpretation, in which Mary likes herself. If we assume that all that is required for interpretation of an ellipsis is that the ellipsis refer to an antecedent, and thus that an ellipsis is a copy of its antecedent, we fail to explain the ambiguity of (32), nor can we predict that (33) has only a "sloppy" reading.

Also, there are many examples in which an ellipsis is not parallel to its antecedent, evidence that underscores the idea that ellipses are not interpreted under syntactic identity, or reference, with those antecedents. (See Chao [1987: ch. 4] for discussion of this phenomenon in a government-binding framework, and Hankamer and Sag [1976] for an opposing view.)

(34) The children asked to be squirted with the hose, so we did [e] (Chao 1987: 134).

(35) The children asked to be squirted, but we didn't know with what [e] (ellipsis in CP: Chao 1987: 117).

(36) John called out the children's names, and each/all/only Mary's [e] answered (ellipsis in NP: Lobeck n.d.).

In interpretive models compatible with government-binding theory, the content of an ellipsis, identical in sense rather than reference to its antecedent, is argued to be recovered through "reconstruction" of the ellipsis under a different kind of identity relation. Reconstruction applies at either LF (May 1985; Larson and May 1990; Fiengo and May 1990, 
1991; Kitigawa 1991; Hestvik 1992), or S-structure (Lappin and McCord 1990; Lappin 1991). This operation has the effect of "copying in" not the actual surface representation of the antecedent, but rather the logical representation of that antecedent. ${ }^{8}$

In a reconstruction model it is possible to claim that ellipses are basegenerated empty categories, as originally proposed by Wasow (1972) and further justified by Williams (1977), Lappin and McCord (1990), and Lappin (1991). (For an alternative analysis within a reconstruction framework, see Fiengo and May [1990, 1991]. See also Ross [1967], Hankamer and Sag [1976], Sag and Hankamer [1984], and Sag [1976], who argue in favor of a deletion analysis.) Under such an approach, ellipses are therefore empty categories at S-structure in the same way as pro, and we would expect ellipses also to be required to be licensed and identified, just as other empty categories must be. However, from the above discussion it appears that ellipses are "identified" through reconstruction. They therefore appear to contrast with empty NP pronominals such as those in (29) and (30) above, empty categories whose referential content is recovered through "phi" features of person and number."

In the following section I outline arguments from Lobeck (1990, 1991a) that show that ellipses are nevertheless subject to a version of (27); that is, ellipted categories must be not only head-governed, but governed by an X-0 specified for certain features. Therefore, even though the full content of an ellipsis is recovered through reconstruction, a principle similar to (27) still plays a crucial role in licensing and identification of this type of empty category.

\section{The ellipsis licensing principle}

Consider once again (1)-(3), repeated here:

(37) a. Because [Pavarotti couldn't [e]], they asked Domingo to sing IP VP

the part.

b. Mary wants to leave but [Sue doesn't [e]]. IP VP

(38) a. Although John's friends were late to the rally, [Mary's [e]] arrived on time. NP $\quad \mathbf{N}^{\prime}$

b. Mary enjoyed the movies, and [both [e]] were also interesting NP $N^{\prime}$ to Sue. 
(39) a. We want to invite someone, but we don't know [who [e]]. CP IP

b. Mary decided to go to Hawaii though she wouldn't tell us [why [e]].

CP IP

At first glance, it does not appear that all of the empty categories in (37)-(39) are head-governed, an observation that might lead us to conclude that the hypothesis that such empty categories are subject to (27) is untenable. In (37) the empty category is governed by INFL, a head filled with a modal in (37a) and with pleonastic do in (37b). If INFL is empty in the above examples, ungrammaticality results. It therefore seems reasonable to claim that ellipted VPs in tensed clauses must be headgoverned by filled INFL. A similar claim cannot be extended to ellipsis in NP in any immediately obvious way, however. In (28a), the empty category is introduced by a phrase in SPEC(N) position (Jackendoff 1977), and in (38b) by a quantifier, an element that Jackendoff (1977) also analyzes as a specifier. Similarly, in (39), the ellipsis is introduced by a WH-phrase in SPEC(C), if we assume, following Chomsky (1986a), that WH-movement is to this position. It is not obvious, then, whether it is possible to maintain that ellipted categories are governed by $\mathrm{X}-0$ heads, at least not under certain current assumptions.

Another set of data that must be considered in a discussion of the conditions on licensing and identification of ellipted categories includes evidence that ellipsis in a range of other categories is ungrammatical in English. For example, ellipsis in AP, PP, VP, and $\mathrm{N}^{\prime}$ is ill formed, though in each case [e] is governed.

(40) *John is anxious to leave, and Mary is also [eager [e]].

$$
\text { AP CP }
$$

(41) *I went to the table, and put the book [down [on [e]]].

PP PP DP

(42) *John acts crazy, and sometimes Mary [seems [e]] too.

VP AP

(43) *Even though [the [students [e]] were bored, the professor of NP $\mathrm{N}^{\prime} \quad \mathrm{PP}$

chemistry kept on lecturing.

The data in (37)-(43) illustrate that though ellipsis in CP and IP is allowed, ellipsis in NP is allowed only under certain conditions, and ellipsis in AP, PP, and VP is completely ruled out. Also, there does not seem to be evidence that in all of the grammatical cases the ellipsis is 
head-governed. It is thus unclear how we might derive constraints on ellipsis from a broader licensing principle such as (27).

Lobeck (1991a) argues in detail that ellipted categories in NP, CP, and IP are in fact head-governed, but that this claim can only be made by adopting a theory of phrase structure that incorporates the "DP hypothesis", whereby noun phrases are headed by DET rather than $N$ (Fukui and Speas 1986; Abney 1987). Under this approach, the ellipses in (37)-(39) are uniformly the complements of the functional X-0s INFL, DET, and COMP, illustrated schematically in (44):

(44) a.

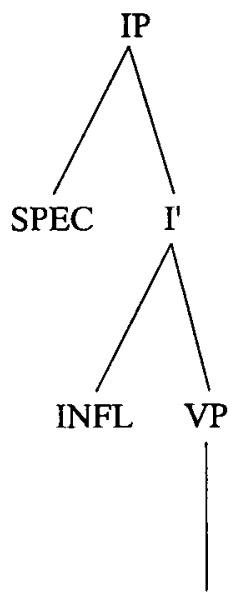

[e] b.
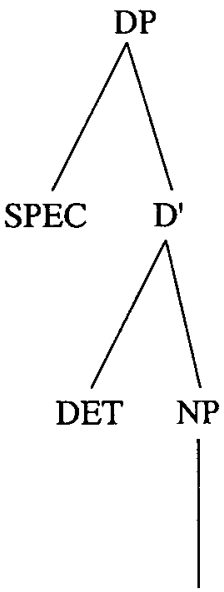

[e] c.
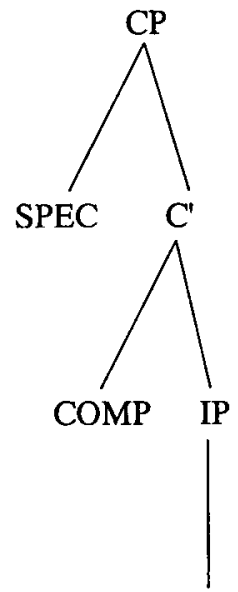

[e]

Furthermore, with certain details aside for the moment, it is possible to argue that the "functional" heads DET, COMP, and INFL can be either lexically filled or specified for certain features. Assuming that an X-0 is a governor when either of these conditions is met, tensed INFL, filled with a modal in (37a) and auxiliary do in (37b), governs ellipted VP. Similarly, in (38a), DET specified for the feature [+Poss], realized as 's in English following Fukui and Speas (1986) and Abney (1987), is also a governor. In (38b), DET lexically filled with the quantifier both governs its empty NP complement. Finally, in sentences in which SPEC $(C)$ is filled with a WH-phrase, Chomsky (1986b) proposes that under such conditions, COMP is specified for the feature [+WH] (see also Fukui and Speas 1986; Rizzi 1990; and Chomsky 1989, 1992). COMP [+WH], specified for a feature, governs ellipted IP in (39).

From the above analysis of the grammatical sentences in (37) (39), ellipses appear to be required to satisfy part of (27): they must be headgoverned. If we further restrict ellipses to being well formed only if head- 
governed by a functional category, we explain the ungrammaticality of the sentences in (40)-(43); in each case, the empty category is governed by a lexical ( $A, P, V$, and $N$, respectively) rather than functional head.

The evidence I turn to next suggest that requiring ellipses to be headgoverned by functional heads is not enough; the ellipsis is well formed only when head-governed by a functional category specified for certain features.

Consider the following paradigm of ellipsis in what we can now analyze as DP:

(45) a. The students attended the play but [most/some/all/both/two [e]] went home disappointed. DP

b. Some candidates from Seattle came to the party, and only [those [e]] talked to Mary. DP

c. The fact that [John's [e]] was poorly presented made the DP committee adopt Mary's analysis instead.

d. *A single protester attended the rally because [the [e]] DP apparently felt it was important.

e. *Sue toyed with the idea of buying a surfboard, then decided she didn't want [a [e]] after all.

\section{DP}

f. *A candidate from Seattle came to the party, and only [that [e]] talked to Mary. DP

g. *The candidates walked in and [every [e]] sat down.

DP

h. *Because [new [e]] hurt his feet, Nick wears only old Reeboks. DP

We immediately explain the ungrammaticality of $(45 \mathrm{~g})-(45 \mathrm{~h})$ by adopting Contreras's (1989) claim that every in English fills SPEC(N) rather than DET, a claim Fukui and Speas (1986) make for prenominal adjectives. The empty categories in these cases are thus not head-governed, and if head-government is required of ellipted categories, we explain why they are ruled out.

To explain the contrast between the grammatical sentences in (45a)-(45c) on the one hand, and the ungrammatical (45d)-(45f) on the other, Lobeck (1991a) argues that ellipted NP is only well formed when 
governed by DET specified for certain features, namely [+Plural] or $[+$ Poss $] .{ }^{10}$

That DET in (45a)-(45b), filled with a quantifier, numeral, or plural demonstrative, is [+Plural] is illustrated by the evidence that $\mathrm{N}$ must in these cases also be plural. Plurality is typically realized on $\mathrm{N}$ by the morpheme $-s$ in English.

(46) a. quantifier: most/some/all/both books/*book [+Plural]

b. numeral: two/six books/*book [+Plural]

c. plural demonstrative: those books/*book [+ Plural]

In (45d), DET filled with the definite article the is unspecified for plurality, and thus unspecified for agreement altogether; consequently, the $\mathrm{N}$ head of the complement of DET can be either plural or singular.

(47) definite article: the books/book [unspecified]

By proposing that empty NP must be governed by DET [+ Plural] to be well formed, we correctly predict that the empty NP complement of DET is grammatical in (45a)-(45b) and ruled out in (45d)-(45f). Continuing under the assumption that only DET specified for certain features allows an ellipted complement, we predict the grammaticality of (45c) if empty NP is also well formed when governed by DET [+ Poss].

Ellipsis in CP exhibits a similar asymmetrical distribution, one that is also explained by proposing that only empty IP governed by COMP specified for certain features will be grammatical. While COMP [+WH] can introduce ellipted IP in (48), COMP filled with a lexical complementizer, that, for, whether, or if in (49), fails to do so.

(48) a. Even though Mary's not sure [who [e]], she knows someone CP IP

is speaking tonight.

b. Sue asked Bill to leave, but [why [e]] remains a mystery.

CP IP

c. Although [how [e]] is still unclear, Sue thinks that John CP IP

made it to work on time.

(49) a. *Even though Mary hopes [that [e]], she wonders if anyone CP IP

interesting is speaking tonight.

b. *Sue asked Bill to leave, but [for [e]] would be unexpected.

CP IP

c. *Although [whether/if [e]] is unclear, Sue thinks John made CP IP

it to work on time. 
As explained in detail in section 4.1.3, by restricting the set of appropriate head-governors for empty IP to include only COMP [ $+\mathrm{WH}]$, we derive the well-formed sentences in (48) and exclude the ungrammatical ones in (49).

Finally, there is a split between well-formed and ill-formed ellipted constituents in IP. Empty VP governed by INFL [+Tense, + AGR], realized by a tensed auxiliary, a modal, or some form of pleonastic $d o$, is well formed:

a. Mary left but [John couldn't/didn't [e]]. IP VP

b. Mary is leaving because [her friends are [e]]. IP VP

c. Although [Mary hasn't [e]], her friends have all read Tolstoy. IP VP

In contrast, empty VP in infinitives, in which INFL is filled with infinitival to, is grammatical only in certain cases, a fact first pointed out by Zwicky (1981) (see note 2). For example, ellipsis in an extraposed infinitive, but not an infinitival subject, is grammatical, as illustrated in (51):

(51) a. Mary doesn't smoke because it's dangerous [PRO to [e]]. IP VP

b. *Mary doesn't smoke because [PRO to [e]] is dangerous. IP VP

(52) illustrates that in contrast to ellipsis in the infinitives in (51), ellipsis in an extraposed tensed clause is grammatical, as is ellipsis in a tensed clausal subject.

(52) a. It's possible that Mary smokes, but it's certain [that John does [e]]. IP VP

b. It's possible that Mary smokes, but [that John does [e]] IP is certain.

Ellipsis also exhibits an asymmetrical distribution in adjuncts; ellipsis in the tensed adjunct in (53a) is grammatical, but ill formed in the infinitival adjunct in (53b):

(53) a. John took off work so that he could go on vacation, and Bill left his job [so that he could[e]] too.

$$
\text { IP VP }
$$

b. *John took off work to go on vacation, and Bill also took some time off [PRO to [e]].

$$
\text { IP VP }
$$


The above data suggest that ellipsis exhibits a subject-adjunct versus object asymmetry in infinitives that doesn't exist in tensed clauses. Lobeck (1987b, 1991a) derives this distinction by claiming that only INFL [+Tense] is a possible proper governor for ellipted VP. INFL [-Tense], on the other hand, must "inherit" proper government from a higher verb. Inheritance is possible only under government and is thus only available in postverbal infinitival complements or extraposed infinitives, but not in infinitival subjects or adjuncts. This analysis correctly predicts that ellipsis in tensed clauses is uniformly grammatical when INFL is filled, while ellipsis in infinitives is far more restricted.

Putting the above claim a bit differently, I propose here that lower untensed INFL must "inherit" features from higher tensed INFL under government, and that it is only when this happens that the empty VP complement of untensed INFL will be well formed.

Summarizing, we have seen that an ellipsis is allowed only when governed by a head specified for certain features. This condition resembles, but is not identical to, (27), as the latter is defined in terms of agreement features, where agreement does not include the features for which the governors of well-formed ellipses are specified. Rather, ellipses appear to be subject to a principle better expressed as (54).

The ellipsis licensing principle (ELP) (Lobeck 1991a):

An ellipsis must be governed by a functional head specified as [+Plural ], [+Poss], [+Tense, +AGR], or [+WH].

The ELP explains the data under discussion and further suggests that an ellipsis, like NP, or now more accurately DP pro, must be governed by a head specified for certain features. Furthermore, the analysis of ellipsis in infinitives suggests that in certain cases, the governor of an ellipsis, like the governor of argument pro, can "inherit" features from a higher coindexed element and consequently is an appropriate licensing head for an empty pronominal category.

Note that the ELP as stated makes the correct prediction that ellipsis will be ruled out in lexical categories in English, predicting the ungrammaticality of the sentences in (40)-(43), as only functional heads are potential licensing heads for ellipted categories. Observe, however, that we need not even specify that the only potential licensing heads for ellipted categories are functional categories; lexical categories will automatically be excluded from licensing ellipses in English, as these categories are not specified as [+Plural], [+Poss], [+Tense, +AGR], or $[+\mathrm{WH}] .{ }^{11,12}$ We can thus restate (54) more accurately as (55): 
(55) The ellipsis licensing principle (ELP):

An ellipsis must be governed by an $\mathrm{X}-0$ specified as [+ Plural], [+ Poss], [+ Tense, +AGR], or [+WH].

\section{Deriving the ELP}

The ELP bears an obvious resemblance to the condition on licensing and identification of NP pro in (27). In the following section I argue that both (27) and the ELP fall under a broader licensing and identification condition, namely (56).

(56) Licensing and identification of empty pronominals:

An empty nonarbitrary pronominal must be governed by X-0 specified for strong agreement.

As I show, in order for (56) to express conditions on both DP and non-DP pro, agreement, and by extension also strong agreement, must be redefined.

\subsection{Defining strong agreement}

The feature specification in the ELP, [+Plural], [+Poss], [+Tense, $+\mathrm{AGR}]$, and [+WH], are all in a broad sense "agreement" features, if we define agreement informally as in (57):

(57) Agreement:

A head $Y$ is specified for agreement iff $Y$ shares features with another head or phrase that it governs.

According to (57), any grammatical feature is potentially an "agreement" feature, expanding agreement to include not only "phi" features of person, number $([+/-$ Plural $]$, see note 10$)$, and gender, but also, for example, any SPEC-head agreement feature (Chomsky 1986b: 24), or other grammatical feature shared between an X-0 and another constituent. Further, if we continue to assume that "strong" agreement is defined as in (58), any morphologically realized agreement feature is now potentially a "strong" agreement feature.

(58) Strong agreement:

An X-0 is specified for strong agreement iff

(i) the X-0, or a phase or head coindexed with it, is specified for agreement and 
(ii) agreement is morphologically realized on $\mathrm{X}-0$ or on the phrase or head coindexed with it.

In the following sections I discuss the functional categories DET, INFL, and COMP in turn and demonstrate that when specified for certain features, namely those listed in the ELP, these heads are specified for strong agreement under (57)-(58). Empty DP and non-DP pronominals are thus both licensed and identified under (56), a more inclusive version of (27).

4.1.1. Strong agreement in DET. That [+ Plural] in English DET can also be analyzable as an agreement feature under (57) is straightforward; the $\mathrm{N}$ head governed by DET [+ Plural] must overtly realize plurality, generally expressed by the affix $-s$. DET [+Plural], lexically filled with either a plural demonstrative, a numeral, or a quantifier, thus morphologically realizes an agreement feature and is, according to (58), specified for "strong" agreement. When DET is negatively specified for agreement, on the other hand, no agreement feature is realized by DET or N. DET in this case is not specified for strong agreement. DET [-Plural], filled with a singular demonstrative or an indefinite article, is therefore not specified for strong agreement. DET filled with a definite article in English lacks specification for plurality altogether and is, for this reason, also not potentially specified for strong agreement. ${ }^{13}$

As for DET [+Poss], according to Abney (1987) and others, DET [+Poss] is specified for a case feature, an agreement feature under (57). We have two possible analyses of the means by which DET [+Poss] is specified for strong agreement. DET itself may morphologically realize the affix ' $s$, which is then affixed to an NP in SPEC(D) at some point during the derivation, presumably PF. Alternatively, ' $s$ might be viewed as a "spellout" of the genitive case feature [+Poss] on that specifier. DET [+ Poss] would then not itself morphologically realize agreement but, rather, would be coindexed with a phrase that morphologically realizes this feature. DET $[+$ Poss] is then specified for strong agreement under (58ii).

Adopting the system in (57)-(58), it is therefore possible to maintain that, of the category DET, only DET [+ Plural ] and [+ Poss] are specified for strong agreement in English, and, therefore, only such DET will under (56) license and identify an empty NP complement. ${ }^{14}$

This analysis of strong agreement in DET is independently justified by data from German, a language in which DP exhibits a distribution of ellipted categories similar but not identical to that in English. To illustrate, consider (59): 
(59) a. Er liest den/seinen/einen Artikel heute und ich lese den/ seinen/einen [e] morgen.

He reads the/his/an article today and I read the/his/a [e] tomorrow.

b. Er liest viele Artikel aber ich lese zwei/wenige/weniger [e]. He reads many articles but I read two/few/less [e].

c. Er liest Johanns Buch und ich lese Marias [e]. He reads John's book and I read Mary's [e].

As the sentences in (59) illustrate, DET filled with a plural demonstrative, a numeral, a quantifier, or the feature [ + Poss] allows an ellipted complement. Ellipsis in German DP differs from its English counterpart, however, in that in the former, DET filled with a definite or indefinite article, elements that under the analysis proposed here are [-Plural] and thus not specified for strong agreement, allow ellipted NP complements. We explain this apparent contrast, however, and also preserve the generalization that [-Plural] is not a strong agreement feature, by observing that German DET filled with a definite or indefinite article also lexically realizes gender and case. Such DET are therefore specified for agreement features unavailable in English and, as expected, can license and identify empty NP under (56). ${ }^{15}$

4.1.2. Strong agreement in INFL. Turning next to strong agreement in INFL, recall that only INFL [+ Tense, +AGR], filled with an auxiliary element, allows an ellipted VP complement. This seems to suggest that INFL [+Tense, +AGR], when morphologically realized, is specified for strong agreement. Further support for this claim comes from English infinitives, in which untensed INFL, a head negatively specified for tense and AGR, must "inherit" features of a higher tensed INFL in order to license and identify empty VP.

It is possible, however, to make the conditions under which INFL is specified for strong agreement even more precise. Recall that in English, features of person and number in INFL are not strong agreement features, as these features apparently do not license and identify an empty pronominal DP. Moreover, as first pointed out by Zagona (1982), these features, typically represented as [+AGR], do not contribute in any obvious way to the identification of empty VP. We therefore might not expect them to be the means by which empty VP satisfies (56). The feature [+Tense] in English INFL, on the other hand, is an agreement feature under the broad definition in (57); [ + Tense] is realized in INFL by an auxiliary element, or on $\mathrm{V}$ by verb raising or affix hopping. Furthermore, in all the well-formed cases of ellipsis in tensed IP in English, INFL is lexically 
filled by have, be, do, or a modal. ${ }^{16}$ It is thus possible to claim that when lexically filled, INFL [+ Tense] is under (58) specified for strong agreement. If this is the case, we explain the productivity of empty VP, but not of empty DP subjects, in English; INFL realizes [+ Tense], but not agreement features of person, number, and gender in the appropriate way to license and identify an empty pronominal. English INFL is thus specified for strong agreement, but only for strong agreement features relevant to the well-formedness of empty VP.

The irrelevance of the role of person, number, and gender features in licensing and identification of ellipted VP is underscored by the evidence that in languages in which INFL lacks these nominal agreement features, ellipted VP can nevertheless be well formed. Md. Salleh (1987) argues for the existence of an INFL node in Malay, a head that is specified as [+ Tense] but lacks standard agreement features of person, number, and gender. As he points out, tensed INFL in Malay allows an ellipted VP complement.

(60) Ahmad boleh memandu kereta, dan Mary boleh [e] juga. VP

Ahmad can act-drive car, and Mary can $\underset{\mathrm{VP}}{\mathrm{e}] \text { too. }}$

'Ahmad could drive a car, and Mary could also.'

(61) Saya tidak pernah menonggang kuda, tetapi John telah

I not has act-ride horse, but John already

[e] pernah.

VP

[e] has.

VP

'I have never ridden a horse, but John has.'

Based on this evidence, it is more accurate to say that it is the [+ Tense] feature of INFL, realized by an auxiliary element, that designates INFL as specified for strong agreement under (58) in the relevant way to license and identify empty VP in Malay, an analysis that extends straightforwardly to English. As for ellipsis in infinitives, (58) correctly predicts that untensed INFL will license and identify empty VP only when coindexed with a higher INFL [+Tense]. ${ }^{17}$

Pursuing the above analysis a step further, we correctly predict that ellipsis of the VP complement of a lexical category will not be allowed in English, a language in which lexical heads are governors, but not specified for strong agreement, in particular, for the feature [+Tense]. We thus explain the ungrammaticality of the sentences in (64), in which 
a VP complement of a lexical head, rather than of an inflected functional head, is ellipted:
a. *Because Mary continued [e], John also started speaking VP French.
b. *Although she never makes John [e], Mary makes Sue write her papers on the computer.
c. *We saw John dance but we couldn't watch Mary [e]. VP

\section{VP}

In (62a), the complement of a temporal aspect verb is ellipted, with an ungrammatical result. Emonds (1985) argues in detail that such complements are VPs. Under the current approach, the evidence that such VPs cannot be empty suggests that $\mathrm{V}$ is not an appropriate licensing or identifying head for the empty category in such cases. This in turn follows if only an X-0 specified for strong agreement, in particular, for the morphologically realized feature [+ Tense], licenses and identifies ellipted VP. If we assume that affixation of the feature Tense to $V$ is at PF and at S-structure (and also LF, for that matter), the possible level(s) at which licensing and identification must be satisfied, $V$ is not specified for strong agreement, and ellipsis is ruled out. Similarly, the VP complement of causative make in (62b) and of the perception verb watch in (62c) do not appear to license and identify ellipted VP, a result that follows as empty VP must be governed by INFL that lexically realizes [+ Tense] to be well formed.

4.1.3. Strong agreement in COMP. Turning finally to sluicing, recall that this operation is productive in indirect questions as in (48), in which empty IP is governed by COMP [+WH] coindexed with a WH-phrase in SPEC [C]. We might propose, then, that COMP [+WH] is specified for strong agreement and licenses and identifies empty IP, satisfying (56). This is certainly plausible, as COMP coindexed with a WH-phrase in SPEC $(C)$ is not only [+WH] but is also specified for SPEC-head agreement, according to Chomsky (1986: 27). This [+WH] feature in COMP can therefore be considered a strong agreement feature under (58), as COMP is coindexed with a phrase in SPEC that morphologically realizes that feature.

One issue that must be addressed if we assume that COMP is specified for strong agreement in the way described above is why it is that COMP $[+\mathrm{WH}]$, filled with a lexical WH-complementizer whether or if in English, fails to license and identify an ellipted complement, as we see by the ungrammaticality of (63): 
*Although [whether/if [e]] is unclear, Sue thinks John mate it to CP IP

work on time.

COMP $[+\mathrm{WH}]$ in (63) differs from COMP $[+\mathrm{WH}]$ in the grammatical cases of sluicing in other indirect questions in (48) in that in the former, COMP is not also specified for SPEC-head agreement. This is illustrated by the ungrammaticality of cases in which COMP is filled with whether or if, and SPEC(C) is filled with a WH-phrase.
a. ${ }^{\prime} I$ wonder $\left[w^{\prime} o_{i}\right.$ [whether $\left[\mathrm{t}_{\mathrm{i}}\right.$ met Mary] $]$ ].
b. *I wonder [what $t_{i}$ [if [Mary saw $t_{i}$ ]]]. CP $\quad \mathrm{C}^{\prime} \mathrm{IP}$

It appears, then, that $[+\mathrm{WH}]$ alone is not a strong agreement feature. It is, however, a strong agreement feature when it is also a SPEC-head agreement feature.

Rizzi's (1990) theory of agreement in COMP offers a further means by which to test the conditions under which COMP is specified for SPEC-head agreement, and therefore a means by which to test the above analysis of sluicing. He argues that only COMP specified for SPEC-head agreement will license an embedded subject trace. Thus, a test for SPEC-head agreement in COMP is whether extraction from the subject position of the clause headed by COMP is allowed. Following Rizzi's diagnostic, COMP in indirect questions, where subject extraction is allowed, is specified for SPEC-head agreement.
a. I wonder [who $\left[\right.$ AGR $\left[t_{i}\right.$ left]]]?
$\mathrm{CP}$
IP
b. I know [what ${ }_{i}$ [AGR [t $t_{i}$ bothers Mary]]]. CP IP

COMP filled with whether or if is not so specified; while extraction of an object out of a clause headed by such COMP apparently violates subjacency, extraction of a subject, which is ungrammatical, also violates the ECP.
a. $\quad \mathrm{Who}_{\mathrm{i}}$ do $\mathrm{I}$ know $\left[\mathrm{t}_{\mathrm{i}}\left[\right.\right.$ whether/if $\left[\right.$ John likes $\left.\left.\left.\mathrm{t}_{\mathrm{i}}\right]\right]\right]$ ?
$\mathrm{CP}$
IP
b. *Who ${ }_{i}$ do I know $\left[\mathrm{t}_{\mathrm{i}}\right.$ [whether/if [ $\mathrm{t}_{\mathrm{i}}$ likes John]]]? CP IP

Under Rizzi's approach, COMP in (66) is not specified for SPEC-head agreement, and the subject trace in (66b) is ruled out by the ECP. 
Incorporating Rizzi's analysis into the present model of strong agreement developed here, COMP is specified for strong agreement under (58) only when both $[+\mathrm{WH}]$ and coindexed with a lexical phrase in SPEC(C) that morphologically realizes this feature. This analysis predicts the contrast betwen (48) and (63).

This account also predicts that COMP specified for SPEC-head agreement that is not also coindexed with a lexical WH-phrase in SPEC(C) will fail to license ellipsis. (67) bears out this prediction.

a. ${ }^{*} \mathrm{Who}_{\mathrm{i}}$ do you wonder $\left[\mathrm{t}_{\mathrm{i}}\right.$ [AGR [ $\mathrm{t}_{\mathrm{i}}$ kissed Bill]]]? CP IP

b. *We know someone kissed Bill, but who do you think $\left[\mathrm{t}_{\mathrm{i}}[\mathrm{AGR}[\mathrm{e}]]\right]$ ?

CP IP

In (67b), COMP is specified for SPEC-head agreement, as we see by the grammaticality of subject extraction. COMP fails, however, to license and identify ellipted IP, wich is exactly what we expect if COMP is specified for strong agreement only when both $[+\mathrm{WH}]$ and coindexed with a lexical WH-phrase in $\operatorname{SPEC}(C)$. We are now also able to explain the ungrammaticality of empty IP complements of lexical heads, as in (68): ${ }^{18}$

a. *Even though Mary doesn't believe [e], Sue expects Hortense to be crazy. IP

c. *John seems to be smart, and Mary also appears [e].

d. *Mary doesn't expect Bill to win, but she wants [e].

The verbs in (68) are neither $[+\mathrm{WH}]$ nor specified for SPEC-head agreement, and empty IP is consequently ruled out.

The analysis proposed here can be extended to French and German, languages that, like English, allow subject extraction in indirect questions, and in which COMP $[+\mathrm{WH}]$ is in such constructions thus in a SPEC-head agreement relation with a phrase in SPEC(C). COMP is thus specified for strong agreement under (58):

(69) Marie savait que quelqu'un avait volé le livre, mais elle

Marie knew that someone had stolen the book, but she n'avait pas deviné qui/quand [e].

IP

NEG-had not found out who/when [e].

'Marie knew that someone had stolen the book, but she hadn't found out who/when.' 
(70) Ich moechte Jemanden einladen aber ich weiss nicht I wanted someone to invite but I know not wen/warum/wie [e].

IP

who/why/how.

'I wanted to invite someone, but I didn't know who/why/how.'

French and German COMP [ $+\mathrm{WH}]$ can also be lexically filled, by $s i$ and $o b$, respectively. Extraction of subjects out of such clauses is blocked, as illustrated in (71):

(71) a. *Qui $i_{i}$ te demandes-tu [ $\mathrm{t}_{\mathrm{i}}$ [si [ $\mathrm{t}_{\mathrm{i}}$ aime Marie]]]?

$$
\text { CP IP }
$$

who CL ask-you if [e] likes Marie

'Who did you ask whether likes Mary?'

b. *Wer $r_{i}$ fragte Hans $\left[t_{i}\right.$ [ob [ $t_{i}$ die Rechnung bezahlen CP IP

who asked Hans whether [e] the bill pay

will]]]?

will?

'Who did Hans ask whether would pay the bill?'

(72) shows that, as predicted, sluicing is also blocked in such clauses, which is what we expect, as COMP is not specified for SPEC-head agreement.

(72) a. *Elle croit vouloir partir mais elle ne sait pas si she believes to want to leave but she NEG know not if [e].

IP

[e].

'She want to go out, but she doesn't know if.'

b. *Hans behauptet er liebe seine Frau. Ich frage mich H. pretends he loves his wife. I ask myself allerdings ob rather whether/if [e].

'Hans pretends he loves his wife. I wonder though if.'

Cross-linguistic data from sluicing thus supports the idea that ellipted categories must be licensed and identified under (56), where agreement is defined as (57), and strong agreement as (58).

4.1.4. Some additional predictions: ellipsis in DEGP. (56) leaves open the possibility that both lexical and functional categories are potential 
licensing and identifying heads for ellipsis, as long as the X-0 is specified for the appropriate strong agreement features. Areas in which we are able to test this hypothesis include lexical categories that take VP and IP complements, complements that we saw could not be empty, as (56) would be violated. The analysis also predicts, again correctly, that other ellipted complements of lexical categories in English will be ruled out, as lexical heads are typically not specified for agreement as defined in (57). In this way we explain the ungrammaticality of the sentences in (40)-(43) above.

Further, we expect the analysis to explain the occurrence or nonoccurrence of ellipsis in functional categories other than DP, IP, and CP. In particular, we expect ellipsis to be possible only if the head of the functional category is specified for some kind of morphologically realized agreement feature(s). As I show below, we find that the analysis again makes the right predictions when applied to the functional category DEGP.

Both Abney (1987: ch. 4) and Corver (1990: ch. 3) argue that certain APs are in fact better analyzed as DEGP, a maximal phrase headed by a degree modifier so, how, much, less, too, etc. As the sentences in (73) show, ellipsis of the complement of DEG is ungrammatical in English.

a. *Mary always gets nervous before talks, and this time she was [so [e]] she almost passed out. DEGP AP

b. *Even though John is [less [e]] today, he was extremely DEGP

AP agi-

tated yesterday.

c. *Even though we don't know [how [e]], we know Mary is DEGP AP

quite upset.

Although DEG may govern [e] in the sentences in (73), it does not share features with the head of its AP complement, nor with a phrase in SPEC position. DEG is thus not specified for agreement according to (57) and hence also not specified for strong agreement under (58). Ellipsis in DEGP therefore violates (56) and is correctly ruled out.

It has been widely argued (since Bresnan 1973) that the English inflectional morphemes comparative -er and superlative -est fill SPEC(A) and are affixed to the head of AP during the derivation. Both Abney and Corver consider such affixes to head DEGP, as in (74). Either the affix must downgrade to A during the derivation, or A must move to DEG to be affixed: 
(74)

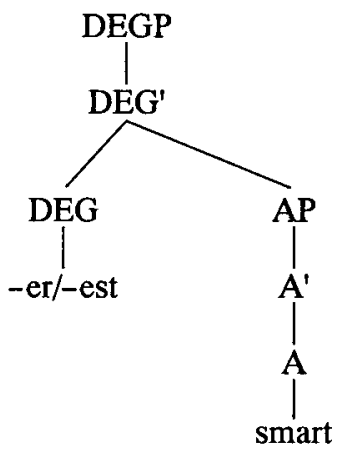

Assuming (74), we might expect ellipsis to be grammatical, as DEG realizes an agreement feature under (57). However, ellipsis is ruled out for independent reasons. Regardless of whether movement of -er/-est is to A, or if A must raise to DEG, ellipsis is predictably blocked in such constructions, as it would require AP to be generated empty, and licensed and identified later in the derivation. Though DEG may be specified for "strong" agreement, affixation of the features of DEG to the head A would never be possible. Such derivations would be ruled out independently, by whatever principle bans unaffixed bound morphemes.

\section{Features and identification}

It follows from most approaches to licensing and identification of empty, nonarbitrary pronominal DP that only features of person, number, and gender supply the content of, or "identify," that referential empty category. The "feature" portion of (56) thus can be taken to express an "identification" condition on empty, referential DP pronominals, and head government can be taken to satisfy licensing. Pursuing the notion of "identification," under (56) as a condition on empty DP and non-DP pronominals, $X-0$ s can realize strong agreement features other than person, number, and gender, and furthermore, we have seen that these features seem to play a role in the identification of empty nonreferential categories other than DP, namely VP, IP, and NP. Across the languages discussed, empty VP is identified under (56) by [+ Tense], and empty IP by the agreement feature $[+\mathrm{WH}]$. Empty NP is identified by [+ Plural] or [+Poss], and as the German evidence suggests, features of gender and case also seem to play a role in identification of the empty complement of DET. Though these features help recover certain grammatical aspects of the content of the ellipted category, they do not 
supply the semantic content of the ellipsis to the same extent that agreement features of person and number identify an empty referential DP pronominal. Rather, the identity of an ellipsis is typically argued to be recovered through reconstruction rather than through reference; therefore, it remains somewhat paradoxical that (56) holds of ellipted categories at all.

I submit here that the evidence that the different means by which (56), is satisfied, for referential DP pronominals and nonreferential, non-DP pronominals, respectively, is expected, given the option in the grammar for the content of an empty pronominal to be recovered either through reference (and thus through syntactic agreement features) or through reconstruction. Empty pronominals that are identical in sense, rather than reference, to their antecedents, and are thus interpreted through reconstruction, need only be made "visible" to this process through the features of the governing head. For this reason, the governing head of an ellipsis must be specified for strong agreement features that supply a minimal amount of grammatical content of the ellipsis. The content of an empty referential pronominal, on the other hand, which is not recovered through reconstruction, must be associated with strong agreement features if interpretation is to proceed.

In this way, we explain why neither reconstruction nor (56) alone are sufficient conditions for the well-formedness of an ellipsis. At the same time, however, we preserve the generalization that ellipted categories are nonnominal pro, constrained by general, independently motivated grammatical principles.

\section{Conclusion}

In this paper I have argued that ellipted categories are empty pronominals that are licensed and identified under government by a head specifed for strong agreement. Independently motivated constraints on empty pronominal DPs thus extend to constrain ellipsis, a desirable result in a principles and parameters grammatical model. The analysis also supports a version of phrase structure that distinguishes lexical from functional heads and independently justifies the claim that ellipses are empty categories at the level at which licensing and identification of pro must be satisfied. Finally, I have shown that although reconstruction might be the means by which the content of an ellipsis is recovered, ellipses must nevertheless be made "visible" through association with an appropriately specified X-0 in order to be well formed. The constraints on ellipsis thus 
derive from a larger, independently motivated framework of licensing and identification and need not be stipulated ad hoc.

Received 27 July 1992

Revised version received

Western Washington University

12 July 1993

\section{Notes}

* I thank the participants of the Ellipsis Workshop in Stuttgart, Germany, March, 1992, for their comments on an earlier version of this paper. This paper has also benefitted from discussion with members of the audience of the Linguistics Colloquium at Tilburg University, March, 1992. Thanks especially Joseph Emonds, Norbert Corver, Arild Hestvik, Riny Huybrechts, and Shalom Lappin. I am also grateful to the reviewers of this journal for their constructive comments. Correspondence address: Department of English, Western Washington University, Bellingham, WA 98225-9055, USA.

1. Fukui and Speas (1986) analyze $[+$ Poss], [+WH], and $[+$ Tense, + AGR] as "Kase" features, which is the term I originally used in formulating the ELP in Lobeck (1991a).

2. Sentences such as (6) are first pointed out by Zwicky (1981) and are discussed by Zagona $(1982,1988)$, who is first to argue that empty VP must satisfy the ECP. Contreras (1989) discusses the ungrammaticality of sentences such as (7) and argues that the empty category violates the ECP. Neither Zagona nor Contreras extends their analyses to ellipsis in other categories, not do they claim that ellipses are empty pronominals as I do here. Chao (1987: ch. 4) proposes that ellipses in both IP and CP are, like empty NP pronominals, licensed under head government by INFL or COMP, respectively. As I show, head government alone is not a restrictive enough condition to rule out several ungrammatical patterns.

3. That (12) is a necessary but not sufficient condition on the occurrence of NP pro is illustrated by the fact that in languages such as German, in which agreement is morphologically expressed fairly systematically, nonarbitrary pro is nevertheless disallowed. See Jaeggli and Safir (1989) for an analysis of why this might be the case. I also omit from the discussion the requirement that pro be case-marked, and the constraints on arbitrary null pronominal objects. See Rizzi $(1982,1986)$, Raposo (1989), and Jaeggli and Safir (1989) for discussion of pro and case, and Huang (1984), Cole (1987), Farrell (1990), and Authier (1989, i.p.) for discussion of constraints on empty pronominal objects. I also assume, following the works cited here, that there exist strategies other than the "agreement" strategy for licensing and identification of pro. My intent here is only to show that ellipses are licensed and identified under an agreement strategy, just like certain types of NP pro.

4. For space considerations, I will not include examples of how stripping, gapping, and null complement anaphora pattern differently from what I refer to here as ellipsis. My claim is that although these other processes might conform to certain of the criteria discussed below, none but ellipsis conforms to all of them. For additional relevant discussion see Ross (1967), Wasow (1972), Jackendoff (1977), Napoli (1983), Sag and Hankamer (1984), Chao (1987), and Lobeck (n.d.).

5. One case of ellipsis that may not conform to the analysis proposed here includes antecedent-contained deletions. I will not discuss such constructions here. See Haik 
(1987), Baltin (1987), May (1985), Larson and May (1990), Fiengo and May (1990, 1991), Lappin and McCord (1990), and Lappin (1991).

6. I assume that only individuals can be referential, and that NPs are individuals, while other categories are not. As Lappin (1992) points out, that ellipted VPs are not referential is also suggested by evidence that empty VP does not share the same distribution as its pronominal counterpart. This suggests that an ellipsis is crucially different from a pronoun with respect to its relation to its antecedent. See also Fiengo and May (1991) for discussion.

(i) a. The presentation of this material in a straightforward way is possible, and often I do *[e]/it.

b. (After the speaker performs an action)

Now you do ${ }^{*}[\mathrm{e}] / \mathrm{it}$.

As for sluicing, IP, semantically a proposition not an individual, can by definition not be referential. A nominal projection that undergoes ellipsis, a phrase that excludes the determiner/specifier position, is also not referential, as the reference of NP depends on the properties of the determiner introducing that NP.

7. I discuss only empty VP here for exposition. See Williams (1977) and Chao (1987: ch. 4) for discussion of the interpretation of ellipsis in CP, an empty category whose content is recovered in the same way as the ellipted constituent in IP. Williams, following Wasow (1972), also makes this claim for the ellipted category in NP (for Williams, an empty category derived through "one's deletion").

8. "Reconstruction" is executed in different ways in different works. For Partee (1973) and Williams (1977), reconstruction yields representations expressed in terms of lambda notation. Most recent analyses dispense with lambda notation, although there is by no means a consensus on exactly how the reconstruction mechanism is to be stated. I am assuming either that the correct formulation of reconstruction will be able to account for nonparallelism data, or that discourse processes interact with reconstruction to account for such data (see Chao [1987: ch. 4] for a possible model of interpretation incorporating both reconstruction and discourse processes). In any case, the point here is that syntactic "copying" of an antecedent into an ellipted category is not an adequate means of recovering the content of the empty category.

9. Reconstruction is not necessarily unavailable for pronouns. Chao (1987: ch. 4), citing Kempson (1986), points out that the pronoun in (i) probably requires reconstruction:

(i) "John always gives his profits to overseas aid, but Sam uses them to expand his business.

In (i), the pronoun them may be interpreted as Sam's profits, the "sloppy" reading of the antecedent his profits. This reading is presumably unavailable without reconstruction, as a strict copy of the antecedent would result in only the strict interpretation.

10. The notation $[+/-$ Plural $]$ is equivalent to $[+/-$ Number $]$ if the latter is taken to mean $[+$ Number $]=[+$ Plural $]$, and $[-$ Number $]=[-$ Plural $]$.

11. Lexical categories are not typically specified for these features at $S$-structure, where the ELP in (55) applies. Lexical categories may, however, be specified for these features after certain post-S-structure processes have applied. For example, affix hopping or verb raising may apply to affix tense and AGR to $V$, and $N$ may be affixed with plural $-s$ at some post-S-structure level. See Lobeck (n.d.) for a detailed analysis of these processes and their interaction with the ELP.

12. Some possible counterexamples to the generalization made here include empty NP discussed by Farrell (1992) and illustrated in (i)-(ii): 
(i) What a beautiful song. Who was the composer [e]?

(ii) This car is being sold by the owner [e].

Farrell argues that [e] in (i)-(ii) is pro. Also, Zribi-Hertz (1984) argues that the complement of certain $P$ in French is best analyzed as pro.

(iii) Cette valise, je voyage toujours avec [e].

This suitcase, I always travel with [e].

Under the present analysis we do not expect such cases, as neither $\mathrm{P}$ in French nor $\mathrm{N}$ in English, the relevant governing heads of pro in these cases, is specified for features according to the ELP. These cases might therefore be evidence of an alternative strategy for licensing and identification of pro.

13. It is conceivable that a negative agreement feature could in theory be a potential strong agreement feature. For example, if the $\mathrm{N}$ head-governed by DET [-Plural] in a particular language morphologically realized agreement distinct from both the realization of [+Plural] and a lack of specification for plurality, we might take [-Plural] in DET to be a strong agreement feature. In English, however, DET [-Plural] occurs only with the unmarked form of the noun, suggesting that there is no overtly realized agreement relation between DET and $\mathrm{N}$.

14. For exposition I consider here only the features [+Poss] and [+Plural] in DET as strong agreement features. This analysis is, however, refined in Lobeck (n.d.), as it fails to capture certain contrasts between singular and plural DET. For example, the singular quantifier each and the singular numeral one in fact allow ellipted complements, in contrast to singular DET filled with the indefinite article $a$ :

(i) The candidates came in and each/one/*a [e] sat down.

To explain why certain singular quantifiers and numerals allow ellipted complements I argue that in addition to the feature [+ Plural], the feature [+Partitive] is also a "strong" agreement feature. Though each, one, and $a$ are all [-Plural], each and one are distinguished from $a$ in also being [+ Partitive]:

(ii) $e a c h / o n e / * a$ of the men

We therefore derive the correct distribution of empty categories in DP in English by positing that [+Plural] and [+ Partitive] are strong agreement features. Extending this analysis to the singular quantifier every, we explain why this quantifier fails to allow an ellipted complement, without positing, as I have above, that every fills $\operatorname{SPEC}(\mathrm{N})$ and is therefore not a possible licensing head.

(iii) *The candidates came in and every [e] sat down.

Under an analysis in which the features [+Plural] and [+ Partitive] are strong agreement features, we predict that every will fail to allow an ellipted complement, as this quantifier is both [-Plural] and [-Partitive] (every man $/{ }^{*}$ men, *every of the men) and therefore not specified for strong agreement. See also Lobeck (1991b) for discussion of agreement in DET.

15. Van Riemsdijk (1989) discusses a different type of empty category in German DP and suggests further that such empty categories are derived through movement and "regeneration."

(i) Einen Wagen hat er sich noch keinen [e] leisten koennen. a car has he refl yet none afford could (As for cars, he has not been able to afford one yet.) 
Van Riemsdijk argues that in (i), $N^{\prime}$ is topicalized, and that the features of the head of $N^{\prime}$ (count, gender, number, case) determine the lexical form of the determiner "regenerated." There is thus a type of "strong" agreement requirement involved in regeneration, and thus a possible interesting connection with ellipsis, which I will not pursue here.

Other cases of ellipsis in German DP that I will not address are given in (ii)-(iii):

(ii) Ich moechte das alte Buch kaufen aber Sie moechten das Neue.

I wanted the old book buy but you wanted the new.

'I wanted to buy the old book but you wanted to buy the new one.'

(iii) Ich sah alle von ihnen, und jedes [e] war sehr teuer.

'I saw all of them, and each [e] was very expensive.'

In (ii), the adjective neue is [-Plural], but is specified for both case and gender. It may be analyzed as either a specifier (Fukui and Speas 1986) or a head (Travis 1988). Under the latter analysis, that neue allows an ellipted complement is predicted, as the adjective is specified for strong agreement features of case and gender. In (iii), the quantifier jeder ('each/every') in German allows an ellipted NP complement, in contrast to its English counterpart. This is again predicted, as jeder is in German inflected for case and gender. Jeder is also [+ Partitive] and for this reason is specified for strong agreement according to the analysis outlined in note 14.

16. I am assuming here that modals are [+ Tense], the view also taken by Pollock (1989) and Chomsky (1989). Emonds (1985: ch.5) proposes, however, that modals are $[-$ Tense, $+/$-Past $]$, while tensed auxiliaries are $[+$ Tense, $+/-$ Past $]$, and infinitives are unspecified for these features. In his system, it is more accurate to say that the feature [+/-Past], rather than the feature $[+$ Tense], is the relevant strong agreement feature that designates INFL as a licensing and identifying head for ellipted VP.

17. Ellipsis is of course also blocked in many languages in which INFL is [+Tense], such as French, German, and Spanish. Such languages differ from both English and Malay, however, in exhibiting productive verb raising. Lobeck (1987a, n.d.) argues that ellipsis is ruled out in such languages by the interaction of verb raising and the ECP. See Zagona (1988) for an alternative analysis of the lack of ellipsis in Spanish IP.

18. Examples of what can bé analyzed as "stripping" (Ross 1967) might at first appear to involve grammatical cases of ellipted IP. These may not seem to be explained by the present approach, as IP is not governed by COMP [+WH].

(i) If he is here in time, he will get the money, and if not, not.

(ii) John plays the piano.

Yes, but not very well.

I show in other work, following both Hankamer and Sag (1976) and Chao (1987), that the phenomenon illustrated in (i)-(ii) is not "ellipsis" of the sort under discussion here, as it does not conform to the criteria discussed in section 2 . For example, stripping does not always seem to involve a constituent (for example, empty IP), which we see by the schematic "reconstruction" of (i)-(ii) in (iii)-(iv).

(iii) If he is here in time, he will get the money, and if (he is) not, (he will) not (get the money).

(iv) John plays the piano.

Yes, but (he does) not (play) very well.

Note also that the "empty category" in stripping contexts cannot precede its antecedent and thus differs from what $I$ define here as ellipsis. 
(v) "If not, not, but if he is here in time, he will get the money.

(vi) *Though not very well, John plays the piano.

\section{References}

Abney, Steven (1987). The English noun phrase in its sentential apsect. Unpublished doctoral dissertation, MIT. (Distributed by MIT Working Papers.)

Authier, Jean-Marc (1989). Arbitrary null objects and unselective binding. In The Null Subject Parameter, Osvaldo Jaeggli and Ken Safir (eds.), 45-68. Dordrecht: Kluwer.

-(i.p.). A parametric account of V-governed arbitrary null arguments. Natural Language and Linguistic Theory.

Baltin, Mark (1987). Do antecedent-contained deletions exist? Linguistic Inquiry 18, 579-595.

Borer, Hagit (1989). Anaphoric AGR. In The Null Subject Parameter, Osvaldo Jaeggli and Ken Safir (eds.), 69-110. Dordrecht: Kluwer.

Bresnan, Joan (1973). Syntax of the comparative clause construction in English. Linguistic Inquiry 4, 275-345.

Chao, Wynn (1987). On Ellipsis. University of Massachusetts, Amherst: Graduate Linguistics Students Association.

Chomsky, Noam (1982). Some Concepts and Consequences of the Theory of Government and Binding. Cambridge, MA: MIT Press.

-(1986a). Knowledge of Language: Its Nature, Origin and Use. New York: Praeger.

- (1986b). Barriers. Cambridge, MA: MIT Press.

-(1989). Some notes on economy of derivation and representation. MIT Working Papers in Linguistics 10, 1-32.

-1992). A minimalist program for linguistic theory. Unpublished manuscript, MIT.

Cole, Peter ( 1987). Null objects in universal grammar. Linguistic Inquiry 18, 597-612.

Contreras, Heles (1989). On Spanish empty $\mathrm{N}^{\prime}$ and N. In Studies in Romance Linguistics, Carl Kirschner and J. DeCesaris (eds.). Amsterdam: Benjamins.

Corver, Norbert (1990). Evidence for DEGP. In Proceedings of NELS 20. University of Massachustts, Amherst: Graduate Student Linguistics Association.

Emonds, Joseph (1985). A Unified Approach to Syntactic Categories. Dordrecht: Foris.

Farrell, Patrick (1990). Null objects in Brazilian Portuguese. Natural Language and Linguistic Theory 8, 325-346.

-(1992). Null noun complements in English. Linguistic Inquiry 23, 147-156.

Fiengo, Robert; and May, Robert (1990). Anaphora and ellipsis. Paper presented at GLOW, Cambridge University.

-; and May, Robert (1991) Indexing and Identity. Cambridge, MA: MIT Press.

Fukui, Naoki; and Speas, Margaret (1986). Specifiers and projections. MIT Working Papers in Linguistics 8, 128-172.

Grinder, J.; and Postal, Paul (1971). Missing antecedents. Linguistic Inquiry 2, 269-312.

Haik, Isabelle (1987). Bound VPs that need to be. Linguistics and Philosophy 10, 503-530.

Hankamer, Jorge; and Sag, Ivan (1976). Deep and surface anaphora. Linguistic Inquiry 7, 391-426.

Hestvik, Arild (1992). The effect of subordination on strict identity interpretation of reflexives. In Proceedings of the Stuttgart Ellipsis Workshop. University of Stuttgart.

Huang, C.-T. James (1984). On the distribution and reference of empty pronouns. Linguistic Inquiry 15, 531-574. 
--(1989). Pro-drop in Chinese. In The Null Subject Parameter, O. Jaeggli and K. Safir (eds.), 185-214. Dordrecht: Kluwer.

Jackendoff, Ray (1971). Gapping and related rules. Linguistic Inquiry 2 (1), 21-36.

-(1977). X-bar Syntax. Cambridge, MA: MIT Press.

Jaeggli, Osvaldo; and Safir, Ken (eds.) (1989). The Null Subject Parameter. Dordrecht: Kluwer.

Kempson, Ruth (1986). Logical form: the grammar cognition interface. In Communication et Cognition: Documents de Travail, Colloque des Cargese. Paris: CNRS.

Kitigawa, Yoshi (1991). Copying identity. Natural Language and Linguistic Theory 9, 497-536.

Langacker, R. (1966). On pronominalization and the chain of command. In Modern Studies in English, D. A. Reibel and Sanford Schane (eds.). Englewood Cliffs, NJ: Prentice-Hall.

Lappin, Shalom (1991). Concepts of logical form in linguistics and philosophy. In The Chomskian Turn, A. Kasher (ed.), 301-333. Oxford: Blackwell.

- (1992). The syntactic basis of VP ellipsis resolution. In Proceedings of the Stuttgart Ellipsis Workshop, University of Stuttgart.

; and McCord, Michael (1990). Anaphoric resolution in slot grammar. Computational Linguistics 16, 197-212.

Larson, Richard; and May, Robert (1990). Antecedent-containment or vacuous movement: reply to Baltin. Linguistic Inquiry 21, 103-122.

Lobeck, Anne (1987a). Syntactic Constraints on VP Ellipsis. Bloomington: Indiana University Linguistics Club.

$-(1987 b)$. VP ellipsis in infinitives: INFL as a proper governor. In Proceedings of NELS 17. University of Massachusetts, Amherst: Graduate Students Linguistics Association.

- (1990). Functional heads as proper governors. In Proceedings of NELS 20. University of Massachusetts, Amherst: Graduate Students Linguistics Association.

-(1991a). The phrase structure of ellipsis. In Syntax and Semantics, vol. 25, Susan Rothstein (ed.). New York: Academic Press.

- (1991b). Spec-head agreement in DP. In Proceedings of the West Coast Conference on Formal Linguistics 10, Dawn Bates (ed.). Stanford: CSLI.

- (n.d.) Ellipsis: functional categories, licensing and identification. Unpublished manuscript.

May, Robert (1985). Logical Form: Its Structure and Derivation. Cambridge, MA: MIT Press.

Md. Salleh, Ramli (1987). Fronted constituents in Malay: base structures and move-alpha in a configurational non-Indo European language. Unpublished doctoral dissertation, University of Washington.

Napoli, Donna Jo (1983). Missing complement sentences in English: a base analysis of null complement anaphora. Linguistic Analysis 12, 1-28.

Partee, Barbara (1973). Some transformational extensions of Montague Grammar. Journals of Philosophical Logic 2, 509-534.

Pollock, Jean-Yves (1989). Verb movement, universal grammar, and the structure of IP. Linguistic Inquiry 20, 365-424.

Raposo, Eduardo (1989). Prepositional infinitival constructions in European Portuguese. In The Null Subject Parameter, Osvaldo Jaeggli and Ken Safir (eds.), 45-67. Dordrecht: Kluwer.

Rizzi, Luigi (1982). Issues in Italian Syntax. Dordrecht: Foris.

- (1986). Null objects in Italian and the theory of pro. Linguistic Inquiry 17, $501-557$.

- (1990). Relativized Minimality. Cambridge, MA: MIT Press.

Ross, John Robert (1967). Constraints on variables in syntax. Unpublished doctoral dissertation, MIT. 
Sag, Ivan (1976). Deletion and Logical Form. Bloomington: Indiana University Linguistics Club.

-; and Hankamer, Jorge (1984). Toward a theory of anaphoric processing. Linguistics and Philosophy 7, 325-345.

Travis, Lisa (1988). The syntax of adverbs. In McGill Working Papers in Linguistics: Proceedings of the IVth Workshop on Comparative Germanic Syntax. Montreal: McGill University.

van Riemsdijk, Henk (1989). Movement and regeneration. In Dialect Variation and the Theory of Grammar, P. Beninca (ed.). Dordrecht: Foris.

Wasow, Thomas (1972). Anaphoric relations in English. Unpublished doctoral dissertation, MIT.

Webber, Bonnie (1978). A formal approach to discourse anaphora. Unpublished doctoral dissertation, Harvard.

Welcomat (1992). The Welcomat, Feb. 5, 25.

Williams, Edwin (1977). Discourse and logical form. Linguistic Inquiry 8, 103-139.

Zagona, Karen (1982). Government and proper government of verbal projections. Unpublished doctoral dissertation, University of Washington.

-(1988). Verb Phrase Syntax: A Parametric Study of English and Spanish. Dordrecht: Kluwer.

Zribi-Herz, Anne (1984). Orphan Propositions in French and the Concept of "Null Pronoun." Bloomington: Indiana University Linguistics Club.

Zwicky, Arnold (1981). Stranded to and phonological phrasing. Linguistics 20 (1/2), 3-58. 